\title{
Patrimônio Territorial: Abordagens Teóricas e Indicativos Metodológicos para Estudos Territoriais
}

\author{
http://dx.doi.org/10.21527/2237-6453.2020.52.12-32
}

Recebido em: 9/4/2020

Aceito em: 20/5/2020

Valdir Roque Dallabrida ${ }^{1}$

\begin{abstract}
RESUMO
O patrimônio territorial é aqui concebido como o conjunto de ativos e recursos, materiais e imateriais, que se acumularam ao longo da história num determinado território, resultante de processos históricos de construção e reconstrução socioeconômica e cultural na relação com o entorno ambiental. Inclui tanto os elementos herdados do passado longínquo quanto os que se sobrepõem ao território constantemente. Apesar de sua importância, o tema ainda é pouco estudado no Brasil e na América Latina. Com o propósito de amplificar sua divulgação junto aos pesquisadores e estudantes e instigar novas investigações, recorreu-se à literatura disponível, explicitando-se as principais abordagens teóricas sobre patrimônio, patrimônio territorial e patrimonialização, incluindo, também, as visões críticas. Adicionalmente, são apresentadas sugestões de questões que possam motivar novas investigações. Conseguiu-se acessar dezenas de publicações, posto que as principais contribuições teóricas provêm de autores que se filiam à linha de pensamento da Escola Territorialista Italiana. Com base nas concepções dos autores referenciais, pode-se concluir que tomar o patrimônio territorial como ponto de partida e diretriz no planejamento ou elaboração de estratégias localizadas de desenvolvimento, é seguir no caminho para superarmos análises setoriais e avançarmos rumo a um retorno ao território, ou seja, adotarmos uma abordagem territorial de desenvolvimento. Palavras-chave: Território. Patrimônio territorial. Patrimonialização. Escola Territorialista Italiana. Desenvolvimento territorial.
\end{abstract}

\section{TERRITORIAL HERITAGE: THEORETICAL APPROACHES AND METHODOLOGICAL} INDICATIVES FOR TERRITORIAL STUDIES

\begin{abstract}
Territorial heritage is conceived here as the set of assets and resources, both material and immaterial, that have accumulated throughout history in a given territory, resulting from historical processes of socioeconomic and cultural construction and reconstruction, in relation to the environmental environment. It includes both elements inherited from the distant past, and those that constantly overlap the territory. Despite its importance, the topic is still little studied in Brazil and Latin America. In order to amplify its dissemination to researchers and students and instigate new investigations, the available literature was used, explaining the main theoretical approaches on heritage, territorial heritage and patrimonialization, including, also, critical views. Additionally, suggestions for questions that may motivate further investigations are presented. We managed to access dozens of publications, and the main theoretical contributions come from authors who are affiliated with the line of thought of the Italian Territorialist School. Based on the concepts of the referential authors, it can be concluded that taking territorial heritage as a starting point and guideline in the planning or elaboration of localized development strategies is to follow the path to overcome sectoral analyzes and move towards a return to the territory, or that is, we adopt a territorial approach to development.
\end{abstract}

Keywords: Territory. Territorial heritage. Patrimonialization. Italian Territorialist School. Territorial development.

\footnotetext{
${ }^{1}$ Doutor em Desenvolvimento Regional pela Universidade de Santa Cruz do Sul (Unisc). Professor da Universidade do Contestado (UnC). http://lattes.cnpq.br/1181379224202943. https://orcid.org/0000-0003-2927-960X. valdirdallabrida@gmail.com
} 
O tema patrimônio territorial é pouco tratado, em especial, nas universidades do Brasil e América Latina, mesmo que nos países europeus, com destaque para a Itália e Espanha, já haja uma discussão avançada.

O presente texto aspira revisar as principais abordagens sobre patrimônio, patrimônio territorial e patrimonialização, com o propósito de publicizar aos pesquisadores e estudantes de Pós-Graduação, em especial do Brasil e América Latina, os diferentes enfoques teóricos sobre o tema. Adicionalmente, pretende-se sugerir questões para investigações que confluam com tais abordagens.

Metodologicamente, o texto resulta de uma revisão bibliográfica que abrangeu publicações brasileiras e internacionais sobre o tema em questão, tendo como fonte principal de consulta o site do Sistema Internacional de Informação Científica da Red de Revistas Científicas de América Latina y el Caribe (Redalyc), além de indicações da bibliografia consultada. Com isso, tem-se consciência de não ter abrangido a totalidade das publicações internacionais, detendo-se nesta fonte por considerá-la suficientemente representativa.

A partir da sistematização da bibliografia consultada, toma-se como indicativo a concepção de patrimônio territorial expressa em Dallabrida (2020). Patrimônio territorial como o conjunto de ativos e recursos, materiais e imateriais, que se acumularam ao longo da história num determinado território, representados pelo sistema produtivo e de infraestrutura, o ambiente natural, a formação humana e intelectual, as expressões culturais e a cultura empresarial, os valores sociais, as configurações de associativismo e as redes de relações, além das institucionalidades públicas, sociais e corporativas, presentes num determinado território. O patrimônio territorial é resultado de processos históricos de construção e reconstrução socioeconômica e cultural e é representado por elementos herdados do passado longínquo, outros (re)construídos mais recentemente, com elementos que se sobrepõem ao território constantemente.

Por entender que a concepção patrimonial de território introduziu na área do planejamento territorial uma significativa inovação no processo de configuração territorial (POLI, 2015), é que, além da evidenciação dos principais embates teóricos sobre o tema, apresentam-se questões para investigações sobre o assunto em questão. ${ }^{2}$

Assim, o texto está estruturado, a partir destas considerações iniciais, em mais quatro partes: (i) a primeira e segunda, sintetizando as principais abordagens teóricas sobre patrimônio territorial, mencionando os diferentes enfoques e as questões críticas, seguidas da discussão sobre patrimonialização; (ii) a terceira, apresentando sugestão de questões de investigação sobre a temática referida; (iii) e a quarta, com as considerações finais. Ainda, por fim, apresentam-se as referências bibliográficas empregadas na confecção do texto.

\section{ABORDAGENS TEÓRICAS SOBRE PATRIMÔNIO TERRITORIAL}

A maior parte da literatura sobre o tema em questão utiliza a categoria conceitual capital territorial. Opta-se, aqui, ressaltar, no entanto, o conceito patrimônio territorial, conforme sentido atribuído ao termo por autores como Magnaghi $(2000,2003,2015)$,

\footnotetext{
${ }^{2}$ Para um aprofundamento quanto às contribuições metodológicas, sugere-se consultar Dallabrida (2020).
} 
Dematteis e Magnaghi (2018) e Poli (2015). Outros autores fazem referência aos bens patrimoniais de um território (CARAVACA; GONZÁLEZ, 2009; CARAVACA; GONZÁLEZ; SILVA, 2005) com sentido próximo.

Mesmo assumindo preferencialmente a categoria conceitual patrimônio territorial ao invés de capital territorial, é importante revisar algumas abordagens sobre o tema em questão. Camagni (2009) já fazia uma introdução ao conceito de capital territorial relacionando-o com as condições de competitividade regional. Capello, Caragliu e Nijkamp (2009) aludiam ao conceito de capital territorial para fazer referência a todos os bens, públicos e privados, de um determinado recorte territorial. Para os autores, o capital territorial cumpriria um papel importante na definição do desempenho econômico. Por fim, Caravaca e Gonzáles (2009) propunham ativar o capital territorial, ou seja, os recursos e ativos do território, convertendo aqueles que são genéricos em específicos, como a principal estratégia de desenvolvimento do território. Com sentido assemelhado ao atribuído ao conceito capital territorial, outros autores fazem referência aos bens patrimoniais de um território (CARAVACA; GONZÁLEZ; SILVA, 2005). ${ }^{3}$

Há duas interpretações sobre derivação do termo patrimônio que se entende serem muito mais complementares do que contraditórias. Para Poli (2015), o termo patrimônio deriva do latim patrimonium, conjunto de coisas pertencentes ao pater familias. O sufixo monium, o vincula ao termo alimonium (alimento), introduzindo a dimensão de cuidado, cuidado alimentar (POLI, 2015). Já para Carneiro (2009), a palavra patrimônio é formada por dois vocábulos greco-latinos: "pater" e "nomos". A palavra "pater" significa chefe de família, ou, em um sentido mais amplo, os antepassados. Dessa forma, pode ser associada, também, aos bens, posses ou heranças deixadas pelos chefes ou antepassados de um grupo social. Essas heranças tanto podem ser de ordem material quanto imaterial, posto que um bem cultural ou artístico também pode ser um legado de um antepassado. A palavra "nomos" origina-se do grego; refere-se à lei, usos e costumes relacionados à origem, tanto de uma família quanto de uma cidade. O "nomos" relaciona-se, portanto, com o grupo social. O patri-monio pode ser compreendido, portanto, como o legado de uma geração ou de um grupo social para outro (CARNEIRO, 2009).

O contexto acadêmico do qual surge a discussão sobre patrimônio territorial é o da Escola Territorialista Italiana. Dessa escola originou-se um referencial teórico-metodológico denominado abordagem territorialista ou antropobiocêntrica, cujo propósito foi debater a problemática do território, numa visão multidisciplinar, para servir de base ao planejamento e à gestão do território (ANDRADE; ALMEIDA, 2016). A escola territorialista propõe um "retorno ao lugar" por meio do patrimônio ambiental, territorial e socioeconômico em suas dimensões locais e por intermédio do empoderamento da comunidade, como pilares para um projeto de desenvolvimento local autossustentável (MAGNAGHI, 2010).

Segundo Poli (2015), nas ciências territoriais o patrimônio assume uma conotação geográfica, chamando a atenção não somente aos elementos pontuais (igrejas, edifícios, árvores...), mas ao todo territorial, como uma forma unitária, uma coevolução entre natureza e cultura. Neste sentido, o território passa de suporte para alocar atividades relacionadas aos seus caracteres de patrimônio territorial, assumindo um papel

\footnotetext{
${ }^{3}$ Camagni e Capello (2013) fazem uma profunda revisão sobre capital territorial, destacando conceitualmente todos os elementos que estão incorporados nesse conceito.
} 
proativo no planejamento, resultado de processos históricos de construção e reconstrução. Assim, a concepção patrimonial do território introduziu na área do planejamento territorial uma forte inovação no processo de configuração territorial.

Poli (2015) afirma que o patimônio territorial adquiriu visibilidade no debate sobre as teorias do desenvolvimento local ou territorial, como externalidade positiva ou negativa, e é considerado um avanço em relação à discussão anterior sobre capital territorial ou recurso territorial. Assevera o autor que a inclusão do patrimônio territorial no planejamento leva a um distanciamento em relação a um padrão "economicista" de desenvolvimento, o qual utiliza recursos territoriais (do tipo ambiental, paisagístico, turístico, cultural, etc.) para extraí-los, subsumindo-os dos lugares para inseri-los em um ciclo econômico exógeno, que já produziu novas altenattivas de geração de trabalho e renda, mas também probreza e degradação ambiental. Neste sentido, propõe que se faça uma distinção entre os conceitos de patrimônio territorial, capital territorial e recurso territorial.

Sobre essa diferençiação conceitual Poli (2015) reafirma:

(i) patrimônio territorial é um construto histórico coevolutivo, resultante da reificação e da estruturação de atividades antrópicas que transformaram a natureza em território (MAGNAGHI, 2010), em que os bens materiais, socioeconômicos, culturais e de identidade convergem; o patrimônio é visto como um objeto de transmissão intergeracional e pertence aos bens comuns, sendo, ao mesmo tempo, um estoque de oportunidades resultantes do processo social e base real de aprimoramento social;

(ii) capital territorial é um conceito introduzido inicialmente em documentos da Organização para a Cooperação e Desenvolvimento Econômico (Ocde), e conscentra-se nas especificidades do território e nos diferentes elementos complexos que o compõe, postos em prática para alcançar um alto nível de competitividade econômica;

(iii) recurso territorial é um conceito que qualifica o termo recurso no campo da economia e se refere ao recurso territorial, específico ou genérico, como uma ferramenta para o desenvolvimento.

De qualquer forma, pode-se sintetizar o sentido de patrimônio territorial como o legado ou herança e os meios (materiais ou imateriais) deixados pelos antepassados (chefe de família) de um grupo social aos seus descendentes ou aos contemporâneos.

\section{Patrimônio Territorial como sedimentos materiais e imateriais herdados}

Parte da literatura que trata do tema patrimônio territorial assenta-se sobre a ideia de sedimentos ou heranças do passado. Magnaghi (2010) refere-se ao patrimônio territorial como sendo sedimentos materiais vinculados a morfologias, à fisicalidade dos lugares, às paisagens, mas, também, sedimentos socioeconômicos vinculados aos 
recursos que podem ser ativados nos processos de desenvolvimento, ao conhecimento contextual, ao saber-fazer, às expressões culturais e identitárias vinculadas à memória coletiva, aos valores simbólicos e aos caracteres de pertencimento ao lugar. ${ }^{4}$

O patrimônio assume, portanto, em sua definição territorial, a presença de múltiplos sedimentos das fases anteriores de territorialização, que transformaram a natureza em um território: (i) sedimentos materiais, relacionados às morfologias, à fisicalidade dos lugares, às paisagens; (ii) sedimentos socioeconômicos, vinculados aos recursos que podem ser ativados nos processos de desenvolvimento, conhecimento contextual, conhecimento, habilidades e tecnologias; (iii) sedimentos culturais e de identidade, ligados à memória coletiva, valores simbólicos e características de pertencimento (MAGNAGHI, 2010).

Seguindo a mesma linha de pensamento, para Ortega Valcárcel (1998) a noção de patrimônio territorial parte de um conjunto de recursos culturais e naturais herdados em um dado espaço geográfico, que tem elevado grau de aceitação e reconhecimento social local.

Magnaghi (2015) propõe considerar os bens territoriais (cidades, infraestruturas, paisagens agroflorestais, patrimônio cultural, artístico e arquitetônico...) ou diferentes dimensões do patrimônio territorial como bens comuns, pelo fato de terem sido produzidos por longos processos coevolutivos, por assentamentos humanos e não indivíduos isolados, em sua relação com o ambiente natural. Significa a inclusão do território entre os bens comuns, entre os res commium omnium (coisa comum a todos). Para tal perspectiva, propõe serem pensados sistemas de governança territorial, ${ }^{5} \mathrm{com}$ o fim de "governar os bens comuns", como um autogoverno do território, mesmo admitindo que isso exija repensar regulamentos legais que incidem nos territórios.

Afirma Magnaghi (2015) que esta visão holística, que indica o caminho para o "retorno ao território" e, ao mesmo tempo, para a "reapropriação comunitária dos bens comuns territoriais", não precisa esperar que as soluções "milagrosas" e improváveis da crise se tornem operacionais. Já ocorrem em vários países, à margem e contrastando com a realidade em geral, na forma de processos generalizados de descentralização dos sistemas de decisão públicos e privados. Trata-se de um processo complexo que visa a propor novas formas de desenvolvimento local/territorial, caracterizadas pela crescente ativação de instrumentos de democracia participativa, em que são praticadas formas contratuais e acordos multisetoriais e multifuncionais entre conjuntos de atores, para viabilizar o governo do território como um bem comum. $\mathrm{O}$ autor finaliza a reflexão afirmando: "O substrato do patrimônio territorial praticado sob o 'direito coletivo ao território' está na base desse caminho" (p. 157).

\footnotetext{
${ }^{4} \mathrm{O}$ termo sedimentos não tem o mesmo sentido na língua italiana em relação à portuguesa (como pedaços de solo ou rochas ou até pó que se depositam nas partes baixas do relevo que formam as rochas). O uso do termo pelos autores italianos suprarreferidos, diz respeito aos bens materiais ou imateriais resultantes de acumulação histórica na relação do homem com a natureza e nas suas relações de sobrevivência. Pode-se referir ao acúmulo de valores, de saber-fazer, ou mesmo às infraestruturas construídas pelo homem, ou às paisagens que foram se formando e/ou transformando.

${ }^{5} \mathrm{O}$ tema governança territorial não será abordado neste texto. Para o entendimento do tema sugere-se duas publicações: Dallabrida (2015) e Farinós $(2008,2015)$.
} 
A consideração do território como recurso cultural e econômico deriva de sua recente e progressiva valoração como parte do patrimônio histórico e cultural. A partir desse entendimento é que se passa a considerar o território como patrimônio, em razão da evolução da própria concepção de patrimônio e da progressiva reelaboração do conceito de território. Essa confluência de entendimentos é que, nos últimos anos, possibilita se falar em patrimônio territorial (ORTEGA VALCÁRCEL, 1998). Assim, segundo o autor, em termos geográficos, por exemplo, ao se fazer referência ao patrimônio cultural, ou à dimensão cultural do patrimônio territorial, permite-se avançar do monumento ao território. Ou seja, o monumento, ou outro traço da cultura local, deixa de ser visto como um valor em si mesmo, passando a fazer parte de um todo histórico-cultural e socioeconômico-ambiental: o território.

A partir desta compreensão, o território passa a ser visto como complexo herdado, de caráter histórico, do qual dispomos como legado das sociedades precedentes no devir histórico. Assim sendo, podemos contemplá-lo como patrimônio. Como resultado, "O conceito de patrimônio territorial permite integrar, como construção histórica, os elementos naturais e os componentes artificiais no que é a arquitetura do território histórico" (ORTEGA VALCÁRCEL, 1998, p. 40). Segundo o autor, da mesma forma o território pode ser visto como recurso econômico, como exemplo de capital físico e imobilizado ao longo do tempo: edifícios, espaços produtivos, caminhos e rodovias, vias férreas, canais, aterramentos, infraestruturas hidráulicas, instalações extrativo-minerais, comerciais e industriais. Esses ativos fixos têm um valor contábil. Não anula nem se sobrepõem, no entanto, ao valor simbólico e/ou econômico dos ativos imateriais que compõem o território.

De todo modo, combinam-se elementos herdados do passado longínquo, outros (re)construídos mais recentemente, com elementos que se sobrepõem ao território constantemente, os quais virão a se tornar, mais cedo ou mais tarde, elementos herdados. Os ativos físicos, todavia, têm um valor patrimonial residual, na medida em que o uso ativo do território convive com

[...] uma natural transformação do mesmo, o que provoca o desaparecimento ou desnaturalização da construção territorial precedente. Em conseqüência, as construções territoriais herdadas tendem a ser elementos residuais ou, em todo caso, tramas semiocultas frente aos novos componentes e novas "arquiteturas" do território (ORTEGA VALCÁRCEL, 1998, p. 45).

A questão do valor patrimonial residual dos ativos físicos também é abordada por Feria (2013), justificando que a presença humana tem modificado, em menor ou maior grau, a imensa maioria dos espaços naturais existentes em contextos geográficos de histórica antropização, contribuindo para modelar e introduzir variações sobre as características e fisionomia de ditos espaços, indo desde a alteração das cadeias tróficas até o manejo de massas florestais, passando por sua própria condição de espaços delimitados.

No sentido territorial, o patrimônio territorial é um sistema de relações sinérgicas entre qualidades peculiares ao ambiente físico (clima, flora, fauna, estrutura geo-hidromorfológica, sistemas ambientais), ao ambiente construído (permanências e persistências de longa data, tipos de construção urbana e territorial, técnicas e materiais, qualidade da massa territorial, características da paisagem) e ao ambiente antrópico 
(modelo sociocultural, peculiaridades linguísticas, caracteres do meio). O tratamento do patrimônio territorial, para utilizar seus valores como recursos, requer a construção de estruturas cognitivas capazes de interpretar de forma integrada os três aspectos do patrimônio em si (MAGNAGHI, 2005, p. 10). A esses três aspectos, falta acrescentar o ambiente socioeconômico, incluindo os subsistemas produtivos e a ação social no território, compondo a totalidade do patrimônio territorial.

Poli (2015) concebe o patrimônio territorial como um conceito nômade. Reconhecido no campo jurídico como herança familiar, assumiu, ao mesmo tempo, diferentes significados que produziram sucessivas mudanças semânticas, até a proteção e conservação do patrimônio cultural e da paisagem. Visões economicistas sobre patrimônio territorial têm equiparado o conceito com o termo recurso ou capital territorial. No debate cultural, no entanto, surgiram definições que destacam o significado do patrimônio "como forma de construir o bem comum", que enquadra as atividades econômicas em uma estrutura geral e inclusiva, na qual as relações patrimoniais representam a base de valor para a produção de riqueza duradoura, que constrói, ao mesmo tempo, o elemento de aumento da descoberta ou redescoberta do recurso, que é "[...] a razão da coesão da sociedade no contexto de referência e, ao mesmo tempo, uma limitação à ação destrutiva e individualista do mercado" (p. 140).

Pensar o desenvolvimento dos territórios ou regiões, com o propósito de superar modelos de desenvolvimento que resultam na destruição dos seus contextos de vida, é o que propõe a alternativa territorialista, sustentada na concepção do patrimônio territorial como um bem comum. A abordagem territorialista destaca-se por assumir o território como um sujeito vivo altamente complexo, gerado e definido em sua identidade por processos coevolutivos duradouros entre o assentamento humano e o meio ambiente. "Portanto, nossas propostas de projetos baseiam-se no conhecimento multidisciplinar do território e de seus processos de territorialização, o que permite compreender as regras de transformação e valorização do seu patrimônio" (DEMATTEIS; MAGNAGHI, 2018, p. 15). Os autores propõem renovar os modelos antigos, porém não confiar muito nos novos.

Neste sentido, Dematteis e Magnagui (2018, p. 18-19) propõem diretrizes teóricas de um novo modelo socioeconômico fundamentado na valorização do patrimônio territorial.

a - uma nova civilização hidráulica, ambiental e energética, como precondição ao funcionamento do sistema socioprodutivo local;

b - uma nova civilização agroecológica, na perspectiva da multifuncionalidade e produção de serviços ecossistêmicos;

c - uma nova civilização da hospitalidade, mediante mudanças culturais, um repensar das formas diversas de migração;

d - uma nova civilização urbana, com a reconstituição sinérgica da relação cidade e campo, urbano-rural e a reconstituição de processos de urbanidade inclusiva, como uma nova forma de gerir os bens comuns;

e - uma nova civilização produtiva, contemplando a gestão social, a produção biorregional voltada ao bem-estar das pessoas, com ética e com modelos econômicos alternativos ao domínio exclusivo do mercado; 
f - uma nova civilização empreendedora, com caráter complexo, participativo e inclusivo e pacto do governo com o sistema produtivo local, com mudanças no sistema de tomadas de decisão, com responsabilidade social corporativa, salvaguarda ao emprego e responsabilidade socioterritorial;

g - a construção de novas relações entre o sistema socioterritorial e o mercado, como uma construção social, um mercado não mais regulamentado globalmente, mas por um intercâmbio cooperativo entre diferentes sistemas e mercados regionais.

É uma aposta de retorno ao território, que envolve políticas de solução de problemas nas mais diferentes dimensões - a ambiental, social, administrativa, infra estrutural, paisagística, produtiva, etc. -, que exige novos posicionamentos: (i) o crescimento da consciência de lugar; (ii) o papel inovador, no espectro de produtos, dos setores que contribuam para avanços na perspectiva do patrimônio territorial como bem comum; (iii) a formação de sistemas complexos de tomadas de decisão de natureza pacífica na gestão dos setores inovadores; (iv) empresas que adotam o "princípio territorial" em seu processo de produção para lidar com essa transformação gerencial; (v) empresas que tendam a referir sua produção a um critério multissetorial, de multifuncionalidade, para configurar distritos multissetoriais; (vi) órgãos públicos locais que, dentro desses sistemas socioeconômicos locais, voltados à gestão e ao autogoverno dos bens territoriais comuns, assumem um papel decisivo na organização dos processos e formas de participação do público com base em sistemas complexos de tomadas de decisão e gerenciamento de sistemas socioprodutivos locais (DEMATTEIS; MAGNAGUI, 2018, p. 24).

\section{Patrimônio Territorial como Conjunto Integrado dos Recursos e Ativos Materiais e Imateriais}

Outros autores tratam do tema patrimônio territorial como conjunto integrado e original de ativos e recursos.

Calderón e García Cuesta (2016) referem-se ao patrimônio territorial como um conjunto único e original de combinações naturais e sociais e suas relações entre si. Lembram os autores que o patrimônio territorial constitui uma porção variável de combinações no espaço, sem fronteiras administrativas. O importante, para eles, é que, mais recentemente, se passa da simples valoração de proteção dos recursos com procedimentos e mecanismos para articular os mesmos, com o fim de considerá-los potencialidades nas estratégias de desenvolvimento. Assim, o território é incorporado não mais como recurso ou espaço físico, mas como interconexão na ação humana, com o que o patrimônio territorial passa a ser a expressão do uso que a sociedade faz do espaço. 0 território não é mais simplesmente um suporte ou local de patrimônio, ou um cenário para a paisagem, mas um espaço em que tudo é considerado integradamente como território de patrimônio.

O patrimônio de um território, também, não são os recursos isolados, por exemplo, uma catedral, um castelo, uma tradição, uma paisagem natural, uma forma característica de produzir algo, mas a combinação desses e de outros recursos, resultantes de estável ou cíclica, contínua ou descontínua atividade humana, tudo isso, articulado por meio de uma história singular e original (CALDERÓN; GARCÍA CUESTA, 2016). Assim 
sendo, há uma relação entre os recursos do passado, a herança e o modo de vida do presente, e é necessário reconhecer os valores culturais como resultado de uma construção social (ORTEGA VALCÁRCEL, 1998).

Para Calderón e García Cuesta (2016), portanto, a combinação das diferentes fontes de recursos patrimoniais e a atribuição de valor ao conjunto resultante de todas elas em um território, constitui o patrimônio territorial, o que representa um salto conceitual na avaliação social, política e econômica desses recursos. Para os autores, essa combinação é a soma de momentos irrepetíveis, pois o patrimônio territorial é precisamente o padrão, renovado, muitas vezes, pelo uso que a sociedade fez do espaço. Esse espaço tem sido frequentemente submetido a um número tão grande de agressões que requer alguma forma de proteção para atingir um duplo objetivo: conservar o recurso para as gerações futuras e conseguir sua exploração sem custo adicional, atualmente entendido como padrão de sustentabilidade.

O patrimônio territorial é a soma de todos os recursos e histórias contidos nela. Em alguns casos, são recursos de profundo significado histórico ou cultural que, hoje, ainda podem ser funcionais; ainda há outros casos em que os recursos foram usados em algum momento no passado, mas que mais tarde se tornaram lembranças dos usos que eles tinham. Todos eles compõem a profunda memória territorial, sua memória geográfica (CALDERÓN; GARCÍA CUESTA, 2016, p. 2.153).

Seguindo a mesma linha de pensamento, Feria (2013) considera os recursos do patrimônio territorial como um conjunto de elementos significativos articulados entre si. Ou seja, para o autor, o patrimônio territorial precisa ser entendido não como uma mera adição de objetos, mas como um sistema territorial em que cada recurso tem sentido em seu conjunto como produto da relação histórica entre meio natural e ação humana. Com base em estudos realizados, o autor reafirma a relevância e as possibilidades que oferece a noção de patrimônio territorial, sobretudo como um instrumento para a manutenção e agregação de valor a muitos dos recursos naturais e culturais patrimoniais dos diferentes âmbitos geográficos.

\section{Abordagens sobre patrimônio territorial que apresentam questões críticas}

Recorrendo às abordagens teóricas sobre patrimônio, patrimônio territorial e patrimonialização, algumas delas questionam aspectos relacionados à temática.

Segundo Miroslawa e Córdoba Aguilar (2004), há um desfio a ser enfrentado, resultante do fato de que o patrimônio ou herança é o conhecimento, o produto da cultura e o recurso político. Decorrente dessa compreensão, é necessário analisar por que, nos lugares de vida, se promove e direciona uma e não outra forma de interpretação do patrimônio, ou, ainda, quais são os interesses de tal interpretação. Frequentemente, esse fato leva a esquecer elementos históricos, ressaltar outros, reafirmar tais valores do passado, renegar outros. O risco é que as elites socioeconômicas e políticas dos lugares direcionem a valorização ou esquecimento das heranças, no atendimento de seus únicos interesses, contribuindo para a exclusão de valores, ideias e desejos das populações marginalizadas, excluindo-as ou marginalizando-as. 
Já lembrava Lefebvre (1991) que o espaço é formado e reproduzido de maneira contínua. Assim mesmo, é arena do jogo de diferentes interesses sociais, políticos e geográficos e o patrimônio constitui um elemento-chave em ditos processos de formação e reprodução do espaço. Trata-se de processos que, segundo indica Saquet (2015), viabilizam com crueldade o exercício do poder por um determinado grupo social em um momento espaço-temporal concreto, ou seja, em cada tempo e lugar, em favor de seus interesses grupais.

Mulero (2015), ao se propor fazer uma análise crítica da situação da Andaluzia (Espanha), inicia apontando a dicotomia ainda presente em documentos e projetos de proteção patrimonial, entre patrimônio natural e patrimônio cultural, como uma necessidade de superação. Além disso, o autor refere-se às diferentes terminologias utilizadas em documentos oficiais, tais como proteção de paisagens representativas, paisagens patrimoniais, paisagens protegidas, zona patrimonial. $O$ autor destaca o conceito de zona patrimonial, contida na Lei do Patrimônio Histórico da Andaluzia: "[...] aqueles territórios ou espaços que constituem um conjunto patrimonial, diverso e complementar, integrado por bens diacrônicos representativos da evolução humana, que possuem um valor de uso e desfrute para a coletividade e, no caso, valores paisagísticos e ambientais" (p. 71).

Mulero (2015) ressalta alguns desafios ainda não superados no tratamento de questões relacionadas com o patrimônio territorial ou patrimonialização: (i) necessidade de uma definição mais ajustada e mais bem fundamentada dos elementos que integram o patrimônio territorial; (ii) como gerir, com critérios de integração, um patrimônio territorial com magnitude e diversidade, em um contexto jurídico, considerando a existência de leis setoriais, reguladoras das dimensões natural e cultural?; (iii) a necessidade de avaliar a coerência do discurso em torno da necessidade de uma gestão integrada do patrimônio territorial e sua possibilidade de converter-se em recurso para o desenvolvimento territorial; (iv) finalmente, que escala e âmbito de atuação são os mais adequados para aplicar num processo de gestão integrada do patrimônio territorial?

Tais desafios são considerados por Mulero (2015) como questões que ainda dependem de resolução e consenso. De qualquer forma, uma das principais questões pendentes, segundo o autor, é a necessidade da definição de ferramentas específicas que permitam uma gestão integrada dos elementos essenciais do patrimônio territorial, em âmbitos territoriais concretos. Como conclusões e possíveis luzes, o autor propõe que, ante as ameaças e riscos que o atual contexto globalizador impõe aos territórios, (i) impõe-se a necessidade de maior reconhecimento social dos bens patrimoniais e sobre quais bens assim devam ser considerados, além (ii) da necessidade de, diante da magnitude dos bens e espaços catalogados (que, no caso da Espanha, são muitos), uma reinterpretação do que seja um bem patrimonial, o que implicaria deixar de valorizar-se a proteção específica de elementos isolados, com índole museística, para passar a ser entendida como peça destacada, no entanto imbricada e gerida em seu contexto territorial. Adicionalmente, isso implicaria superar a tradicional separação entre patrimônio natural e cultural.

Sobre a referência feita ao desenvolvimento territorial, esta exige um posicionamento sobre o tema. Opta-se pelo entendimento expressado em Dallabrida (2015, 2017): um processo de mudança continuada, situado histórica e territorialmente, in- 
tegrado em dinâmicas intra/supraterritoriais, sustentado na potenciação dos recursos e ativos locais, com vistas à dinamização socioeconômica e à melhoria da qualidade de vida de sua população. Nesta acepção, portanto, o patrimônio territorial é constituído pelo conjunto de recursos e ativos territoriais, sejam eles de caráter material ou imaterial. ${ }^{6}$

Diante das discussões sobre paisagens e patrimônio territorial, Gómez (2013) defende que um avanço necessário seria passar da concepção de patrimônio paisagístico para paisagens, que adquirem seu valor patrimonial, ou seja, são consideradas paisagens-patrimônio, ou melhor, paisagens patrimoniais. A autora fundamenta-se na acepção de paisagem política ou vernacular, fixando-se mais nesta última, como a paisagem de vida de vizinhos ou comunidades, cuja construção vai ocorrendo de modo sequencial, por isso está submetida a uma temporalidade adequada.

Assim, para Gómez (2013), as paisagens patrimoniais, tratam-se de paisagens que se convertem em patrimônio porque são percebidas, vividas, caracterizadas e transformadas pela população residente, que assim as reconhecem. Uma segunda questão levantada pela autora é: Até que ponto a singularidade das paisagens e suas características se adéquam às seleções hierarquizadas por redes para sua inclusão em catálogos turísticos? Outra refere-se à mercantilização das paisagens na medida em que passam a ser reconhecidas universalmente com valor patrimonial, pois o consumo desenfreado de sítios ou paisagens declarados como patrimônio, pode resultar na destruição das suas características originais e distintas. Finalmente, questiona: Como considerar os povos e culturas que aparentemente não têm como reconhecidas suas paisagens patrimoniais, por não terem palavras para nomeá-las, nem literatura para fazer a narrativa necessária para seu reconhecimento?

Com relação a este último questionamento, Calvente (2018) considera que o conceito de patrimônio territorial é de extrema importância ao se pensar políticas públicas em suas diversas escalas, no entanto defende que, antes de tudo, é necessário buscar a compreensão que as pessoas que moram no lugar têm da ideia de seu patrimônio, permitindo, assim, mudar o foco do estudo sobre o patrimônio do lugar para o estudo sobre o patrimônio a partir da vivência das pessoas do lugar. Essa é uma necessidade premente, pois, segundo o autor, caso contrário, criam-se artificialismos.

Santos (1997) defendia que, mesmo que muitas estruturas territoriais desapareçam, traços podem permanecer, o que chamou de "rugosidades" ou "acumulação desigual de tempos". O autor assim referia-se às rugosidades:

O que, na paisagem atual, representa um tempo do passado, nem sempre é visível como tempo, nem sempre é redutível aos sentidos, mas apenas ao conhecimento. Chamemos rugosidades ao que fica do passado como forma, espaço construído, paisagem, o que resta do processo de supressão, acumulação, superposição, com que as coisas se substituem e acumulam em todos os lugares. As rugosidades se apresentam como formas isoladas ou como arranjos (p. 113).

${ }^{6}$ Em outra obra - Dallabrida, Siedenberg e Fernández (2011) - fazia-se referência ao desenvolvimento como um processo resultante da dinâmica territorial, na forma de processos gestados e geridos a partir da ação articulada de atores públicos e privados. 
Partindo desta compreensão, Calvente (2018) questiona se teriam sobrado rugosidades no modo de vida de populações tradicionais do local estudado, no caso, a população caiçara de Ilha Bela (São Paulo). O autor conclui que, ali, as principais rugosidades, ou seja, os elementos da sua paisagem patrimonial, foram esquecidos ou eliminados, mediante o objetivo mercantilista de transformar tais locais em praias para o desfrute turístico externo. Assim, no caso estudado por Calvente (2018), o que se observou foi uma perda de território, por exemplo, na medida em que o mar, de local para sustento das populações tradicionais pela atividade pesqueira, tornou-se praia para turistas. Houve, portanto, perda do patrimônio e do modo de vida, tanto nas manifestações materiais quanto imateriais; isso, partindo do entendimento da autora de patrimônio como herança de um grupo que, junto com a territorialidade, tem a importante função de construir a identidade territorial. Essa herança é constituída de objetos materiais e também de formas de viver, sentir e pensar o mundo.

Sobre o patrimônio de um lugar ou território, Miroslawa e Córdoba Aguilar (2004, p. 40) assim se referem: (i) é o conjunto de elementos do meio natural e cultural que a sociedade tem adotado como seu; (ii) é inseparável da vida social; (iii) pode ser cambiante e dinâmico e, sendo assim, há que investigá-lo; (iv) muitas vezes chega-se a deformá-lo, com fins mercantilistas; (v) é um elemento permanente no espaço, mesmo que mude seu significado. Assim, para as autoras, o patrimônio pode ser de dois tipos: (i) o intangível, abarcando o conjunto de expressões da cultura tradicional e popular ou folclórica, que se transmite oralmente e vai modificando-se com o tempo; (ii) o material, referindo-se aos objetos construídos por uma sociedade, de acordo com sua escala de valores, originalidade e funcionalidade, aceitos como representantes de uma etapa histórica, convertendo-se em parte da paisagem. Esses tipos de patrimônio, geralmente, ajudam a manter viva a memória dos povos. Segundo as autoras, do ponto de vista geográfico o patrimônio é tratado como recurso e, em tal condição, é um fator de desenvolvimento dos lugares ou territórios. O patrimônio, no entanto, deve ser percebido desde o presente, incorporando-o aos estudos socioeconômicos contemporâneos. Como sendo fenômeno do passado, o patrimônio precisa ser tratado como recurso de um lugar e não como o processo histórico em si.

Considerando que o patrimônio refere-se aos atributos tangíveis e intangíveis do lugar ou território, refletindo as particularidades únicas daquele recorte territorial, isso instiga o geógrafo a buscar respostas de diferentes questões, quando o relaciona aos estudos socioeconômicos do presente. Como é recordado o passado e como é representado e incorporado no presente? Como o passado tem modificado o espaço de vida das pessoas na atualidade? Como o passado influenciou a atividade econômica atual? Conforme Miroslawa e Córdoba Aguilar (2004), para responder essas interrogações os estudos geográficos precisam analisar, entre outras, as manifestações espaciais da cultura popular, a tradição artesanal, a organização, a gênesis e os processos de mudanças das atividades econômicas e de sua percepção atual e futura, buscando entender como a tradição, as ideias, os objetos, o meio ou o entorno, todos juntos e cada um de maneira individual, influem nos processos vitais, cambiantes e dinâmicos contemporâneos. 
Já Tarsi (2019) reporta-se ao patrimônio territorial afirmando que são necessárias mudanças de perspectiva, pois, por exemplo, os estudos urbanos e territoriais foram realizados a partir do Norte, termo usado pela autora para se referir aos países europeus. Ou seja, segundo a autora, urge assumir uma perspectiva desde o Sul, dos territórios mais frágeis. Neste sentido, a mesma tem se envolvido em estudos que propugnam intervenções e políticas destinadas à reconstrução de assentamentos informais e à definição de metodologias efetivas para implicar as comunidades no reconhecimento do patrimônio territorial.

Assim sendo, Tarsi (2019) faz referências à complexa realidade dos assentamentos informais que compõem as metrópoles e megacidades dos países do Sul Global, o que representa um dos desafios contemporâneos mais complexos, tanto para as disciplinas destinadas a governar o território quanto para a sociedade no processo de construção da cidadania democrática plena. Os assentamentos informais são, de fato, territórios que apresentam fragilidade múltipla: (i) do ponto de vista socioeconômico, concentrando a maior parte da população urbana vulnerável; (ii) do ponto de vista ambiental, pois surgem em áreas inadequadas para o assentamento ou próximas a importantes fontes de poluição; (iii) finalmente, do ponto de vista dos direitos civis das comunidades assentadas, que não têm acesso às mesmas garantias e serviços que os demais cidadãos, sendo frequentemente relegados, mesmo culturalmente, às condições de subordinação.

Experiências de apoio em favelas brasileiras mostraram que

A ativação dos processos de participação dos habitantes para a construção de projetos compartilhados é um importante momento de reapropriação da consciência dos valores e problemas do próprio território e, ao mesmo tempo, uma oportunidade de imaginar e desenhar um futuro possível e desejável (TARSI, 2019, p. 154).

Somente sob tais condições é que populações que vivem em territórios frágeis veem condições para pensar nos seus saberes, artefatos e modos de vida próprios, gerando possibilidades de reconhecerem seu patrimônio territorial ou a patrimonialização do território.

\section{ABORDAGENS SOBRE PATRIMÔNIO E PATRIMONIALIZAÇÃO DO TERRITÓRIO}

Há uma concepção instigativa de autor italiano sobre patrimônio, que segue:

O patrimônio é um discurso, ele é parte de um princípio narrativo (por isso ele precisa de narradores), que conta os mitos de origem, que descreve os épicos fundadores e momentos históricos de um grupo ou território. Ele confere à toda realidade social uma consistência temporal (duração) e espacial. Ele a convida a projetar-se para o futuro, formular um projeto coletivo (DI MÉO, 2014).

Linck (2012) afirma que a noção de patrimônio tem algo a fascinar. Se for postulado como uma memória coletiva, o patrimônio poderá ser reconhecido como um patrimônio passado de geração em geração e modelado eles. O patrimônio se constitui, portanto, um sistema estruturado por quadros cognitivos, ao mesmo tempo do indivíduo e do coletivo. "O patrimônio aparece então como uma âncora no passado e na ordem social, como uma capacidade de ação e projeção no futuro e em uma ordem social em construção ou em gestação" (p. 2). 
O termo patrimônio não é adotado em seu sentido atual de registro ou inventário, mas como um processo de ativação, gerenciamento, renovação e, finalmente, apropriação e, mais precisamente, apropriação coletiva. Como nem todos da coletividade têm as mesmas aptidões ou habilidades, a apropriação será desigual, sendo esse um dilema que merece reflexão. Trata-se de uma distribuição desigual dentro do grupo que detém o bem coletivo, segundo suas capacidades para nomear, definir, identificar, acessar, gerenciar, desenvolver, tirar vantagem, transmitir. A ação dos diferentes grupos no processo de articulação de um projeto coletivo refere-se, portanto, à patrimonialização (LINCK, 2012).

O conceito de território, na abordagem territorialista, é entendido como resultado do longo processo de coevolução do sistema natural e do sistema antrópico, um organismo complexo e denso, com recursos sedimentados ao longo do tempo e projetáveis ao futuro (TARSI, 2019). Nesta perspectiva, a patrimonialização trata-se de uma estratégia utilizada para a conservação ou proteção de símbolos e signos culturais ou territoriais, ${ }^{7}$ sejam eles monumentos ou objetos aparentemente banais, cidades, sítios históricos, paisagens naturais, festas, ritmos, crenças, modos de fazer ou o saber fazer próprio de um grupo social, um artesanato, um prato típico ou uma técnica construtiva (JEUDY, 2005).

Na realidade, a territorialização, entendida como o processo de apropriação do território, e patrimonialização, são processos complementares, pois os modos de vida de um povo tornam-se elemento constituidor de um território e as relações sociais no território produzem novas formas de vida, em processos contínuos de produção e reprodução do território. Certas formas de vida, por exemplo, um saber fazer histórico relacionado a um prato típico, pode ser objeto de processos de patrimonialização.

Para Linck (2012), processos de patrimonialização coadunam-se com as perspectivas da sustentabilidade, pois permitem a qualificação patrimonial do ambiente no sentido de transmissão garantida e equitativa, às futuras gerações, de recursos e bens comuns, tanto sociais (bens e valores da civilização) quanto ambientais (recursos bióticos ou abióticos).

Complementarmente, Sonaglio, Zamberlan e Busón (2020) consideram a patrimonialização de territórios uma alternativa para a valorização de bens materiais e imateriais, como estratégia de promoção do desenvolvimento regional e local. Para os autores, tais processos iniciam pela realização de um inventário dos bens patrimoniais tangíveis e intangíveis do território, passando por um processo de apropriação das comunidades e a sensibilização territorial, a fim de que os residentes tenham consciência do seu patrimônio, gerando um sentimento identitário. Adicionalmente, faz-se necessária uma estrutura institucional para proteção e gestão patrimonial, permitindo um impacto positivo no território e seus atores ao longo do tempo.

\footnotetext{
${ }^{7}$ Ou melhor, como signos distintivos territoriais. O tema não será aprofundado neste texto, no entanto sugerem-se duas publicações recentes: Dallabrida (2020) e Covas; Covas; Dallabrida (2019).
} 
Bustos Cara (2004) considera a patrimonialização um processo voluntário que busca incorporar valores socialmente construídos, contidos no espaço e no tempo de uma sociedade particular como parte de processos de territorialização que alicerçam a relação entre território e cultura.

A apropriação e valorização como ação seletiva, individual ou coletiva, se expressa em ações concretas que permitem construir referências identitárias duráveis... A patrimonialização de valores territoriais implica na construção de uma "consciência territorial", que em geral, nas condições atuais tem um caráter representacional e comunicacional (BUSTOS CARA, 2004, p. 11).

Para Román e Varela (2018, p. 87-88), patrimônio é o conjunto de bens (tangíveis e intangíveis) herdados através do tempo, que representam a diversidade cultural e social de um território (construção social), como expressão de uma paisagem em contínua evolução, que se revive, the confere novos sentidos e se ressignifica no presente. Já a paisagem é entendida como "[...] resultado formal de uma combinação dinâmica (tempo) de elementos naturais (físicos, químicos e biológicos) e antrópicos (sociais, econômicos, culturais)". É, ao mesmo tempo, uma realidade física e a representação que culturalmente nós fazemos dela. Segundo os autores, quanto à patrimonialização, para que ocorra tal processo numa paisagem, implica que ocorram vários fenômenos culturais: (i) apreço social; (ii) memória coletiva; (iii) vínculos identitários; (iv) criação de um sentido de lugar. Tais fatores vão além do objeto monumental em si mesmo.

Já Martínez Yanes (2008, p. 251) afirma que a questão essencial em processos de patrimonialização é a "[...] caracterização patrimonial do território e a caracterização territorial do patrimônio". Sustenta-se a autora na compreensão de que uma das pedras angulares das atuais políticas territoriais reside no reconhecimento de que o progresso e a prosperidade estão cada vez mais relacionados com o modo em que cada cidade, região ou território podem ativar seu capital endógeno, no qual o patrimônio territorial constitui-se num significativo potencial. Para tal, segundo a autora, o território precisa ser concebido como novo âmbito de atuação, não um recipiente, revalorizando tanto seus elementos naturais, como econômicos e culturais. Atuação, no sentido de fusionar, vincular, proteger e gerir os diversos elementos patrimoniais presentes no território, reafirmando sua vinculação espacial e dotando-as de novas possibilidades e oportunidades de agregação de valor, por exemplo, a atividade turística.

A caracterização territorial do patrimônio, como resultado esperado, implica: (i) a exigência, no marco do planejamento turístico e das políticas de desenvolvimento regional, de uma explicitação, uma relação e comunicação de todos os recursos existentes em um território, além de averiguação das possibilidades de agregação de valor, além de ampliar sua atratividade; (ii) a demanda social e racional, que exija que as políticas culturais sejam desdobradas de forma paralela e coordenada com as do tipo econômico, com dotação de recursos e infraestruturas; (iii) a descentralização da gestão pública, com competência em matéria de patrimônio e atuação destacada, para criar novos instrumentos de planejamento no âmbito de sua jurisdição; (iv) a necessidade de diversificar as atividades econômicas de localidades ou municípios em crise, articulando-se em torno da concepção de território, com ações integradas, de modo à explorar seus recursos endógenos. $\mathrm{O}$ resultado esperado é que o destinatário principal das políticas 
culturais seja agora o território, como o espaço para onde confluem bens culturais e naturais, sendo que o patrimônio passa a ser um fator, entre muitos, que o caracterizam e contribui no seu desenvolvimento (MARTÍNEZ YANES, 2008).

Já a caracterização patrimonial do território, ou patrimonialização do território, resumidamente, se refere às inciativas de criação de diversos instrumentos de gestão, ordenação territorial e proteção dos recursos culturais e naturais que ocorrem em determinado recorte territorial. Paralelamente, ao revalorizar os bens territoriais, se incorpora novas massas de bens, como a arquitetura popular, as estruturas industriais, as obras públicas e o patrimônio intangível. Outro motivo pelo qual se revaloriza o âmbito territorial é a necessidade de adoção de novos modelos de gestão ou proteção dos bens patrimoniais presentes no território. De qualquer forma, a agregação de valor e rentabilização dos bens culturais à escala territorial, exige um trabalho prévio de planejamento territorial que assegure o uso correto e efetivo do patrimônio, como elemento de desenvolvimento, tanto na dimensão econômica quanto na social (MARTíNEZ YÁÑES, 2008).

O patrimônio territorial está na base de processos econômicos de patrimonialização proativa, embutida no valor de existência do território que produz riqueza duradoura para a comunidade estabelecida. A ação pública também desempenha um papel estratégico no acompanhamento de ações proativas, como valorização do patrimônio, tanto na dimensão de identidade territorial quanto de possuir ferramentas contratuais úteis para constituir projetos de desenvolvimento territorial (POLI, 2015).

Uma visão do patrimônio territorial surge como revelação social consciente e compartilhada dos potenciais complexos (ecológicos, culturais, simbólicos, econômicos) inerentes a um território que origina um processo social de patrimonialização, que pode levar à mobilização de ativos em ações de agregação de valor. Poli (2015) entende a discussão atual sobre patrimônio territorial nos processos de reconhecimento social da patrimonialização, com alguns riscos. Por isso, propõe o que chama de patrimonialização proativa, combinando recurso territorial com identidade. Para tal, aponta a necessidade da presença de quatro fatores territoriais: (i) uma ou mais experiências de recursos territoriais herdados, identificadas pela comunidade; (ii) um processo de ativação do componente de recursos territoriais, de acordo com diferentes trajetórias integradas, no sentido cultural, simbólico e econômico; (iii) um processo simultâneo de fortalecimento do componente de identidade territorial com a presença de atividades de conhecimento simbólico, cognitivo e contextual; (iv) a criação de valor agregado territorial, que não se restringe ao uso e aprimoramento do recurso territorial, mas que cria novas oportunidades para a sociedade local.

\section{PERSPECTIVAS SOBRE TEMAS DE INVESTIGAÇÃO NA TEMÁTICA DO PATRIMÔNIO TERRITORIAL}

Parte-se da concepção de patrimônio territorial expressa neste texto - conjunto de ativos e recursos, materiais e imateriais, que se acumularam ao longo da história num determinado território, representados pelo sistema produtivo e de infraestrutura, o ambiente natural, a formação humana e intelectual, as expressões culturais e a cultura empresarial, os valores sociais, as configurações de associativismo e as redes de relações, além das institucionalidades públicas, sociais e corporativas, presentes num 
determinado território (DALLABRIDA, 2020) -, e, na sequência, pretende-se contextualizar para avançar, propondo indicativos metodológicos. Antes, é necessário esclarecer algo mais sobre tal concepção.

O primeiro esclarecimento é que os referidos ativos territoriais são os fatores em plena utilização, enquanto os recursos são os fatores subutilizados ou, ainda, sem utilização alguma (DALLABRIDA, 2016). O segundo é a identificação do que sejam os componentes do patrimônio territorial.

O patrimônio territorial é o resultado das interações entre seus seis componentes (Figura 1): (i) patrimônio produtivo - recursos financeiros, terras, maquinaria, equipamentos e infraestruturas; (ii) patrimônio natural - as paisagens naturais (que passaram ou não por processos de antropização), solos, minerais, fauna e flora; (iii) patrimônio humano e intelectual - o saber-fazer, a formação acadêmica e profissional, o conhecimento e a criatividade; (iv) patrimônio cultural - valores e códigos de conduta, bens culturais e cultura empresarial; (v) patrimônio social - valores compartilhados socialmente, formas de associativismo e redes sociais estabelecidas localmente; e (vi) patrimônio institucional - institucionalidades públicas e privadas, de caráter social, cultural, político ou corporativo (DALLABRIDA, 2020, 2016).

Figura 1 - Patrimônio Territorial e seus componentes

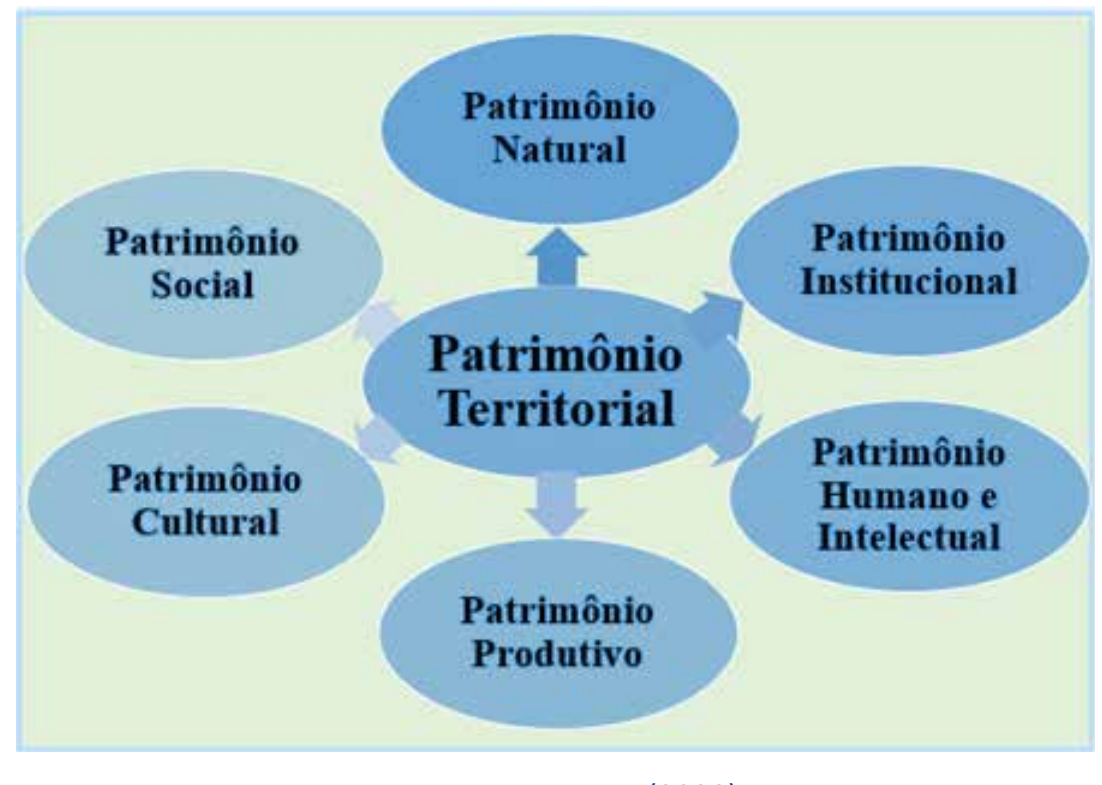

Fonte: DALLABRIDA (2020).

Para fins operacionais, quando da análise de um determinado recorte espacial, os seis componentes do patrimônio territorial também podem ser chamados de dimensões, sendo elas: (i) produtiva; (ii) natural; (iii) humana e intelectual; (iv) cultural; (v) social; e (vi) institucional. Esse conjunto de variáveis, na forma de dados e/ou informações, é indicado para se estruturar um padrão de conhecimentos necessários e suficientes que possam servir de base para estudos com maior profundidade de determinado recorte espacial, seja um município, uma região ou território. O grande desafio é que 
esse padrão de conhecimentos exige um aporte estatístico significativo, além de investigações quantitativas e qualitativas detalhadas, exigindo diferentes instrumentos de pesquisa, além da inserção do pesquisador no contexto em estudo (DALLABRIDA, 2020). ${ }^{8}$

Mesmo considerando a extensão e a variedade das discussões sobre patrimônio, patrimônio territorial e patrimonialização, várias questões podem ser elencadas no sentido de servirem de inspiração para investigações sobre o assunto em referência. Sem ter a pretensão de esgotar o tema, apontam-se alguns questionamentos, os quais resultam das discussões teóricas feitas pelos autores aqui mencionados.

São muitas as interrogações, no entanto mencionam-se as que consideramos mais significativas:

a - Qual é o significado de patrimônio e patrimônio territorial para as pessoas de comunidades com as quais dialogamos nas nossas investigações?

b - Quais os elementos que conformam o patrimônio territorial de um grupo social instalado em determinado território?

c - Partindo da compreensão de que o patrimônio territorial é herança material e imaterial que interfere nas formações socioespaciais do presente, como é recordado o passado e como é representado e incorporado ao presente?

d - Como o passado tem modificado o espaço de vida das pessoas na atualidade?

e - Como o passado influenciou a atividade econômica, as manifestações culturais, o saber fazer atual das populações a serem estudadas?

$f$ - Por que certos lugares de vida são promovidos, preservados, enquanto outros sãos esquecidos? Ocorre isso nos recortes territoriais que são objeto de nossos estudos?

g - A forma de interpretação do patrimônio dos recortes territoriais que estudamos atendem a quais interesses? De todos, ou de grupos definidos dentro da sociedade?

$\mathrm{h}$ - Como as populações marginalizadas consideram seus traços patrimoniais?

i-Qual é a escala ou âmbito de atuação mais adequado para exercer a gestão do patrimônio territorial?

j- No caso concreto das populações tradicionais que descendem dos grupos sociais que se envolveram, por exemplo, no conflito do Contestado, quais rugosidades, ou seja, traços patrimoniais ainda estão presentes? Quais são evidenciadas e quais foram esquecidas?

k - Como refletir sobre a questão do patrimônio territorial com populações de territórios fragilizados, como o caso do Território do Contestado.

I- Em tais populações, quais motivações psicossociais se mantêm, ou quais fatores contribuíram para o esquecimento ou supressão dos elementos patrimoniais?

$\mathrm{m}$ - Outras questões atinentes ao Território do Contestado, como o exemplo das estradas de ferro que atravessavam e interligavam nossas cidades, exemplo de patrimônio material regional, quais motivações contribuíram para seu abandono? A que interesses favoreceu?

\footnotetext{
${ }^{8}$ Em Dallabrida (2020) são apresentados indicativos de fatores e variáveis relacionados ao patrimônio territorial de um recorte espacial, com o fim de serem utilizados como instrumental metodológico para investigações territoriais.
} 
$\mathrm{n}$ - Como os elementos patrimoniais do passado têm influenciado a dinâmica territorial do desenvolvimento atual de territórios? Como é recordado o passado e como é representado e incorporado no presente? Como o passado tem modificado o espaço de vida das pessoas na atualidade?

Essas e muitas outras interrogações podem tornar-se motivação para investigações territoriais.

\section{CONSIDERAÇÕES FINAIS}

Para finalizar este texto, em primeiro lugar ressalta-se que, ao se conceber o patrimônio territorial como ponto de partida e diretriz no planejamento ou elaboração de estratégias localizadas de desenvolvimento (DALLABRIDA, 2020), ou seja, ao se considerar o conjunto de ativos e recursos materiais e imateriais que se acumularam ao longo da história num determinado território como referência, está se propondo que priorizemos análises integradas e renunciemos às análises setoriais. No mínimo, implica que ampliemos ao máximo possível o número de variáveis nos estudos territoriais.

Em segundo lugar, espera-se ter contribuído com este texto para explicitar as principais abordagens sobre patrimônio, patrimônio territorial e patrimonialização, na perspectiva de motivar e desafiar pesquisadores e estudantes, em especial da Pós-Graduação no Brasil e América Latina, onde o tema ainda é pouco investigado. Neste sentido, foram apresentadas sugestões de questões para investigações que confluam com tais abordagens. Estas sugestões podem ser complementadas com contribuições mais detaIhadas realizadas em outra publicação (DALLABRIDA, 2020).

Reconhece-se a necessidade de se ampliar a pesquisa sobre o tema patrimônio territorial, alargando o espectro de fontes de pesquisa a serem buscadas. Como perspectiva, espera-se despertar parcerias institucionais para execução de novas investigações. Em especial, destaca-se a necessidade de conceber instrumentais de pesquisa para a compilação de dados e informações, associando metodologias quantitativas e qualitativas.

\section{REFERÊNCIAS}

ALBERTOS, J. M.; CARAVACA, I.; MÉNDEZ, R.; SÁNCHEZ, J. L. Desarrollo territorial y procesos de innovación socioeconómica en sistemas productivos locales. In: ALONSO, J. L.; APARICIO, J.; SÁNCHEZ, J. L. (coord.). Recursos Territoriales y Geografía de la Innovación Industrial en España. Salamanca: Universidad de Salamanca, 2004. p. 17-60.

ANDRADE, B. A.; ALMEIDA, R. H. Patrick Geddes e a escola territorialista italiana: aproximações conceituais e metodológicas. Pós, São Paulo, v. 23, n. 39, p. 120-137, jun. 2016.

BUSTOS CARA, R. Patrimonialização de valores territoriais. Turismo, sistemas productivos e desarrollo local. Aportes y Transferências, a. 8, v. 2, p. 11-24, 2004.

CALDERÓN, B. C.; GARCÍA CUESTA, J. L. Sources and forms of territorial heritage. International Journal of Humanities and Cultural Studies, v. 3, Issue 1, p. 2.141-2.157, June 2016.

CALVENTE, M. C. M. H. O patrimônio territorial e a perspectiva das populações tradicionais. GeoTextos, v. 14, n. 1, p. 39-60, jul. 2018.

CAMAGNI, R. Territorial capital and regional development. In: CAPELLO, R.; NIJKAMP, P. (eds). Handbook of Regional Growth and Development Theories. Cheltenham: Edward Elgar, 2009. p. 118-132.

CAMAGNI, R.; CAPELLO, R. Regional competitiveness and territorial capital: a conceptual approach and empirical evidence from the European Union. Regional Studies, v. 47, n. 9, p. 1.383-1.402, 2013.

CAPELLO, R.; CARAGLIU, A.; NIJKAMP, P. Territorial Capital and Regional Growth: Increasing Returns in Cognitive Knowledge Use. Timbergen Institute Discussion Papers, 09-059/3, Timbergen Institute, 2009. 
CARAVACA, I. B.; GONZÁLEZ, R. G. Las redes de colaboración como base del desarrollo territorial. Scripta Nova, Barcelona, v. XIII, n. 289, 1ㅇ mayo 2009.

CARAVACA, I.; GONZÁLEZ, G.; SILVA, R. Innovación, redes, recursos patrimoniales y desarrollo territorial. Revista Eure, v. XXXI, n. 94, p. 5-24, dic. 2005.

CARNEIRO, N. P. Memória e patrimônio: etimologia. Webartigos, 11 jul. 2009. Disponível em: https:// www.webartigos.com/artigos/memoria-e-patrimonio-etimologia/21288/. Acesso em: 8 mar. 2020.

COVAS, A. M. A.; COVAS, M. M. C. M.; DALLABRIDA, V. R. Os signos distintivos territoriais e a smartificação do território. Uma abordagem exploratória. Biblio3W - Revista Bibliográfica de Geografía y Ciencias Sociales, v. XXIV, n. 1.268, 20 abr. 2019.

DALLABRIDA, V. R. Governança territorial: do debate teórico à avaliação da sua prática. Análise Social, v. 50 (2ㅇ), n. 215, p. 304-328, 2015.

DALLABRIDA, V. R. Território e Governança Territorial, Patrimônio e Desenvolvimento Territorial: estrutura, processo, forma e função na dinâmica territorial do desenvolvimento. G\&DR - Revista Brasileira de Gestão e Desenvolvimento Regional, v. 16, n. 2, p. 63-78, mai-ago/2020.

DALLABRIDA, V. R. Teorias do desenvolvimento: aproximações teóricas que tentam explicar as possibilidades e desafios quanto ao desenvolvimento de lugares, regiões, territórios ou países. São Paulo: LiberArs, 2017.

DALLABRIDA, V. R. Território, governança e desenvolvimento territorial: indicativos teórico-metodológicos, tendo a indicação geográfica como referência. São Paulo: LiberArs, 2016.

DALLABRIDA, V.; SIEDENBERG, D.; FERNÁNDEZ, V. Desenvolvimento a partir da perspectiva territorial. Desenvolvimento em Questão, v. 2, n. 4, p. 33-62, 14 out. 2011.

DEMATTEIS, G.; MAGNAGHI, A. Patrimonio territoriale e coralità produttiva: nuove frontiere per i sistemi economici locali. Scienze Del Territorio, n. 6, p. 12-25, 2018.

DI MÉO, G. Processos de patrimonialização e construção de territórios. Geosaberes, Fortaleza, v. 5, n. esp. 1, p. 3-23, dez. 2014.

FARINÓS, J. Gobernanza territorial para el desarrollo sostenible: Estado de la cuestión y agenda. Boletín de la Asociación de Geógrafos Españoles, n. 46, p. 11-32, 2008.

FARINÓS, J. D. Desarrollo Territorial y Gobernanza: refinando significados desde el debate teórico pensando en la práctica. Un intento de aproximación fronética. Desenvolvimento Regional em Debate, v. 5, n. 2, p. 4-24, jul./dez. 2015.

FERIA, J. M. El patrimonio territorial: algunas aportaciones para su entendimiento y puesta en valor. E-RPH - Revista Eletrónica de Patrimonio Histórico, n. 12, p. 200-224, jun. 2013.

GÓMEZ, J. Del patrimonio paisaje a los paisajes patrimonio. Documents d’Anàlisi Geogràfica, v. 59, n. 1, p. 5-20, 2013.

JEUDY, H. P. Espelho das cidades. Rio de Janeiro: Casa da Palavra, 2005.

LEFEBVRE, H. The Production of Space. Trad. Donald Nicholson-Smith. Oxford: Basil Blackwell, 1991.

LINCK, T. Économie et patrimonialisation. Les appropriations de l'immatériel. Développement durable et territoires [En ligne], v. 3, n. 3, p. 1-22, Déc. 2012.

MAGNAGHI, A. II progetto locale. Torino: Bollati Boringhieri, 2000.

MAGNAGHI, A. Il progetto locale: verso la coscienza di luogo. Turim: Bollati Boringhieri, 2010.

MAGNAGHI, A. La rappresentazione identitaria del patrimonio territoriale. In: DEMATTEIS, G.; FERLAINO, F. (org.). Il mondo e i luoghi: geografie delle identità e del cambiamento. Torino: Ires; SGI, 2003. p. 13-20. MAGNAGHI, A. Mettere in comune il patrimonio territoriale: dalla partecipazione all'autogoverno". Glocale, Rivista molisana di storia e scienze sociali, n. 9/10, p. 139-157, 2015.

MAGNAGHI, A. Presentazione. II ritorno dei luoghi nel progetto. In: MAGNAGHI, A. La rappresentazione identitaria del territorio. Atlanti, codici, figure, paradigmi per il progetto locale. Florença: Alinea Editrice, 2005. p. 7-18.

MARTÍNEZ YÁÑEZ, C. Patrimonialización del territorio y territorialización del patrimônio. Cuad. Art. Gr., n. 39, p. 251-266, 2008.

MIROSLAWA, C.; CÓRDOBA AGUILAR, H. El patrimonio como tema de estudios geográficos. Espacio y Desarrollo, n. 16, p. 28-41, 2004.

MULERO, A. M. Hacia la gestión integrada del patrimonio en clave territorial: un análisis crítico a partir de la experiencia andaluza. Investigaciones Geográficas, n. 63, p. 69-84, enero-junio 2015. DOI: 10.14198/ INGEO2015.63.05.

ORTEGA VALCÁRCEL, J. El patrimonio territorial: El territorio como recurso cultural y económico. Ciudades: Rev. del Instittuto de Urbanística de la Universidad de Valladolid, n. 4, p. 33-48, 1998. 
POLI, D. II patrimonio territoriale fra capitale e risorsa nei processi di patrimonializzazione proativa. In: MELONI, B. (a cura di). Aree interne e progetti d'area. Torino: Rosenberg e Sellier, 2015. p. 123-140.

ROMÁN, R. A.; VARELA, L. Estrategias desde el proyecto de paisaje para la recuperación de los bienes patrimoniales de la región costera del Gran la Plata. Identidades: Territorio, Cultura, Patrimônio, n. 7, p. 84-100, 2018.

SANTOS, M. A Natureza do Espaço. Técnica e tempo - razão e emoção. 2. ed. São Paulo: Hucitec, 1997.

SAQUET, M. Por uma geografia das territorialidades e das temporalidades. Uma concepção multidimensional voltada para a cooperação e para o desenvolvimento territorial. 2. ed. rev. e ampl. Rio de Janeiro: Ed. Consequência, 2015.

SONAGLIO, C.; ZAMBERLAN, C. O.; BUSÓN, C. Patrimonialização como estratégia de desenvolvimento regional: uma proposta para o "caminho para os ervais". Profanações, a. 7, n. esp., p. 43-60, fev. 2020.

TARSI, E. Patrimonio territoriale, comunità e territori fragili nel Global South. Scienze del Territorio, n. 7, p. 49-156, 2019. 